\title{
EVALUATION OF THE FEASIBILITY OF IMPLEMENTING INNOVATIVE ENERGY EFFICIENT TECHNOLOGIES ON THE WAY OF ECONOMIC DEVELOPMENT OF THE REGION
}

\author{
Liliia Bilous \\ Department of Management and Administration \\ V. N. Karazin Kharkiv National University, \\ 4 Svobody sq., Kharkiv, Ukraine, 61022 \\ l.bilous@karazin.ua
}

\begin{abstract}
Innovative energy efficient technologies are the driving force behind the economic development of the region. The feasibility of introducing such technologies is determined by the degree of innovative development of this region. Today there are a large number of models that substantiate certain indicators used to calculate the integral indicator of an innovative energy-efficient focus. The dynamics of the development of an administrative unit depends on the ability to create favorable conditions for the dissemination and use of innovations, the intensification of scientific and innovative activities. The article also uses the concept of "innovative orientation" rather than "innovative development". The innovation orientation is considered as the degree of intensity and timeliness of the implementation of certain actions by economic entities aimed at innovative development. To calculate the indicator of innovative orientation, the method of integral assessment of innovative orientation is used, which makes it possible to: determine a large number of indicators; explore individual sectors of society; not to analyze generally accepted economic indicators that are not sectoral known in the research subjects, and to determine the energy-efficient focus at the expense of the selected indices of the focus of innovative potential. As part of the study, primary indicators are collected from 14 administrative units of the Kharkiv region. At the next stage of the study, indicators of innovative orientation are determined. In accordance with the principles of conducting research and identifying innovative potential, the indicators are formed in 5 groups. The ranking of integral indicators of innovative energy-efficient orientation is carried out, which makes it possible to reasonably and purposefully give recommendations on energy savings in the studied subjects in accordance with the rank of this index.
\end{abstract}

Keywords: management of economic development, integral indicator of innovative energy-efficient focus, energy efficiency barriers, innovation focus of the region, innovation management.

DOI: $10.21303 / 2504-5571.2020 .001377$

\section{Introduction}

As part of this study, it is necessary to assess the ability of society to reduce the consumption of energy resources on the path of economic growth. In [1], it is described how, using the theory of barriers, one can analyze the direction of development of the non-production sector of administrative units. Research has shown that, first of all, communities overcome technological, technical and material obstacles to the efficient use of energy resources. Grant projects are not aimed at barriers of skills, knowledge, skills and social consciousness. However, the ability to innovative transformations of society ensures the functioning of the system of innovative regional development, it occurs precisely through the acquisition of new knowledge and skills (Fig. 1).

The approach to the development of innovations in the modern world has changed. Earlier, in the era of industrialization, innovation was based on a combination of resources and inventions. In the postindustrial era, the development of strong positive feedback loops of the knowledge production process comes to the fore. The management of information dissemination channels significantly affects the pace of economic, social and cultural development of society. In the context of decentralization, the role of regions has grown, functions are shifting from the center to them in addressing the growing demand for innovation. There is an urgent need to expand innovation networks to overcome global challenges [2].

The aim of research is to assess the feasibility of introducing energy-efficient innovative measures on the example of the Kharkiv region. 


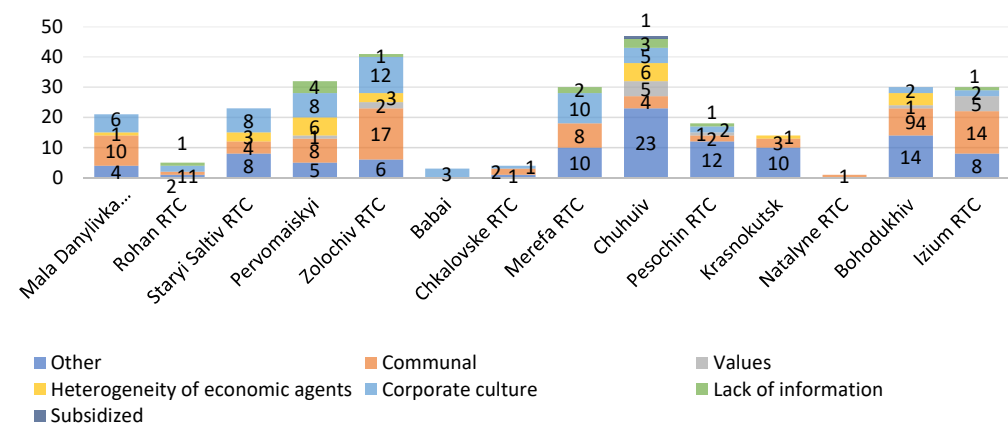

Fig. 1. Intensity of overcoming barriers by the number of projects in 2017-2020 in the studied administrative units

\section{Methods}

There are a large number of methods to determine the innovation orientation of the community as a component of the regional innovation policy. These methods are constantly being updated, adapting to changes in the development conditions of the region. The innovation potential of the region can be defined as technological, economic, intellectual, production, institutional, administrative, research, in general, the integrated ability of the region to combine all its available resources to fulfill external and internal development tasks [3].

The main methods for assessing innovative development are shown in Fig. 2.

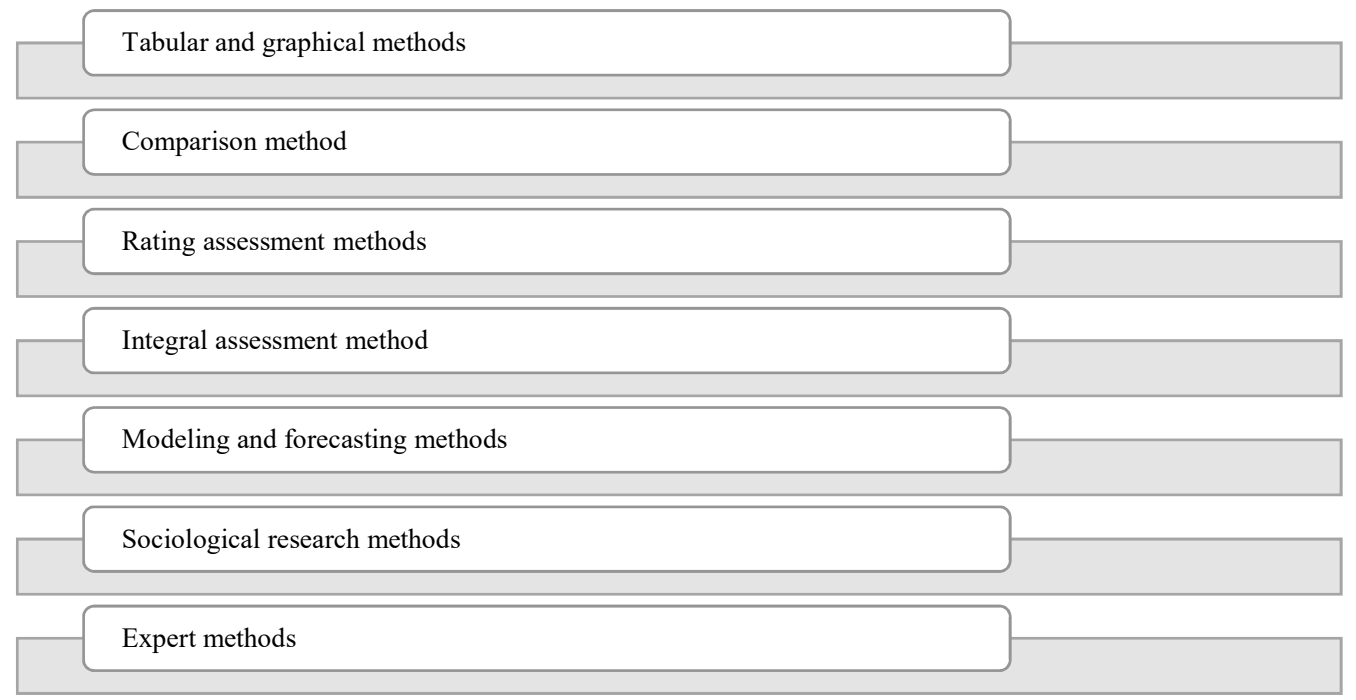

Fig. 2. The most common methods for assessing the innovative potential of regions Source: compiled by the author based on [4]

The complexity of the formation of a system for assessing innovative potential leads to significant methodological difficulties. The mechanism for forming the stages of the assessment and its result itself must meet a number of requirements, which are given in Table 1.

In addition to a principled approach to methods for assessing innovative indicators, it is necessary to apply a comprehensive and systematic assessment. Having worked out the scientific potential of the direction of assessing innovative development, let's come to the conclusion that most scientists are inclined towards the integral assessment method [4]. The most acceptable in our study is the method of integral assessment of innovative orientation, which allows:

- define a large number of indicators;

- explore a separate sector of society;

- not to analyze generally accepted economic indicators that are not known sectorally in the research subjects; 
- ensure the determination of the energy-efficient direction of the research through the selected indices of the direction of the innovative potential.

"Integral assessment of innovation orientation is an indicator in which the values of other indicators are reproduced, adjusted in accordance with their weight and other factors, which allows combining in one indicator many factors that are different in name, units of measurement, significance and other characteristics" [4].

Table 1

Principles for assessing and determining the result of Innovative Potential (IP)

\begin{tabular}{|c|c|c|}
\hline No. & Principles & Content of the requirement \\
\hline 1 & Sufficiency & $\begin{array}{l}\text { The data available should ensure the determination of a sufficient number of indicators that are } \\
\text { involved in the formation of IP indicators, if it is impossible to form the number of indicators, } \\
\text { the scientific approach requires the formation of the most significant }\end{array}$ \\
\hline 2 & $\begin{array}{l}\text { Unambiguity and accuracy } \\
\text { of assessment }\end{array}$ & $\begin{array}{l}\text { The quantitative assessments of the IP should be formed into equivalent groups for all subjects } \\
\text { of assessment and be sufficiently informative to obtain the most accurate result }\end{array}$ \\
\hline 3 & $\begin{array}{c}\text { Completeness of } \\
\text { accounting information }\end{array}$ & $\begin{array}{l}\text { In the study, it is necessary not only to take into account the primary indicators obtained from } \\
\text { the research subjects and their own analysis results for the subjects, but also to use open public } \\
\text { data posted by the subjects themselves and state institutions, which are necessary for the com- } \\
\text { pleteness of the characteristics of the studied subjects }\end{array}$ \\
\hline 4 & Objectivity & $\begin{array}{l}\text { When evaluating individual entrepreneurship, it is necessary to rely primarily on primary in- } \\
\text { dicators and open data obtained from official sources. The IP assessment should be based on a } \\
\text { scientific approach and proven methods }\end{array}$ \\
\hline
\end{tabular}

As a basis for the assessment, let's take the definition of the generalized innovation index (Summary Innovation Index (SII) [5]. In the European Union, this index is calculated as an indicator of the development of innovations in the context of regions. According to the method of calculating SII, the definition of 26 indicators is provided, which have a common name and are divided into five groups of indicators: the development (implementation) of innovations (applications) innovation drivers, diffusion of innovations, knowledge creation of intellectual property [6].

Based on the European method for determining the generalized innovation index (SII), let's approach the study with an understanding of the levels of perfection of the Ukrainian and European socio-economic systems. Taking this into account, under the Ukrainian socio-economic system, it is correct to call the groups of indicators of innovative development as groups of indicators of innovative orientation. Determining the groups of indicators of the innovative orientation of administrative units, let's consider the sufficiency, unambiguity and accuracy of the assessment, the completeness of accounting for information and objectivity. Let's determine the indicators that primarily affect the introduction of energy efficient technologies. Let's define an energy-efficient innovation focus as a set of indicators characterizing the activity of an entity to mobilize its potential to attract grant funds and their targeting. The competitiveness of the studied subjects is formed from the intensity of grant contributions and their focus. Using this technique, let's determine the index of innovation orientation by the method of integral assessment (generalized innovation index) of each investigated administrative unit with a simultaneous rating ranking. This method was chosen because of the possibility of standardizing heterogeneous indicators.

Based on this, let's consistently track the five stages of the study, shown in Fig. 3.

First of all, let's create a base of primary indicators for 14 communities (surveyed subjects). Let's take these indicators of primary data from and analytical data as well as data from passports of communities for 2020 [7]. From these data, let's calculate the indicators that will form the basis of the entire calculation.

At the stage "Formation of initial data" let's systematize all available data into five groups of indicators and form groups of these indicators for each subject of the study separately. All five groups of indicators are present in every research subject. However, different research subjects have a different number of indicators in indicator groups, and the numerical value of indicators in groups has a different dimension, which is determined by: 
- primary data on the consumption of energy resources;

- availability and hunting of development strategies;

- carried out innovative changes;

- targeting of grants and other financial investments;

- development of infrastructure, including through grants.

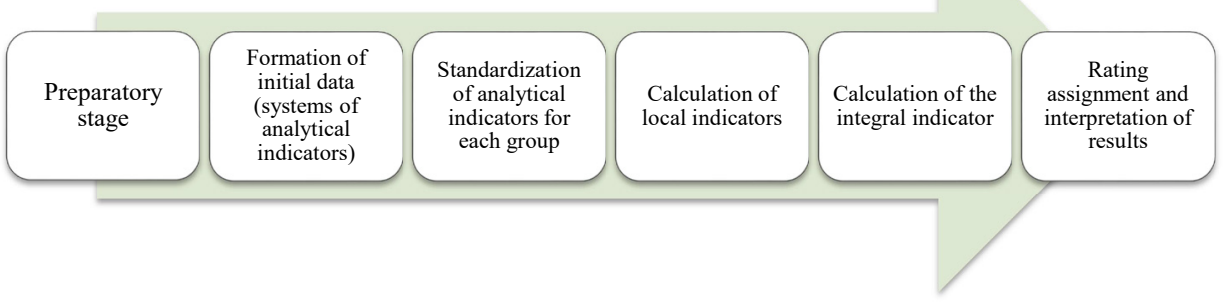

Fig. 3. Research stages

Source: author's development

Calculated from the primary data, 20 indicators are distributed into 5 groups of indicators of innovative orientation, namely:

1. Development (implementation) of innovations. Includes indicators determined by the available investment grant funds aimed in the community on energy saving and energy efficiency, at the same time overcoming energy efficient barriers, promoting the introduction of energy efficient innovative technologies; this also includes the community capacity indicator, which is calculated methodically from community passports, and includes the presence of administrative service centers (ASCs).

2. Economic growth. Including grants aimed at the development of investment infrastructure, and indicators derived from them, this indicator includes funds directed to development, and derived indicators and subsidies. Let's classify this group of indicators as innovative, since, despite the depreciation of fixed assets, the location of the overwhelming number of communities in rural areas, the capital construction of new modern energy-saving facilities is a revolutionary breakthrough.

3. Diffusion of innovations. Defined as overcoming energy efficient barriers in society and the spread of energy efficient changes in society, the diffusion of innovations confirms the intensity of overcoming the barrier. This includes changes in energy consumption and the presence of energy efficient measures in the development strategy of society.

4. Innovation drivers. The leaders of the communities participating in the Covenant of Mayors have been identified. In addition to addressing $\mathrm{CO}_{2}$ pollution issues, this contributes to the creation of regional horizontal ties of economic, cultural and energy efficient cooperation. Energy efficient managers bring innovative energy efficiency knowledge to communities. This is an institutionally well-strengthened line of business, which becomes the center for the diffusion of all energy innovations. The population, acquires secondary education within the community, often remains in the community. Already in high school education they possess information technologies and distribute them in the social environment.

5. Knowledge creation. Creative development is deliberately included in this group, because the indicator of creative development, according to foreign scientists, leads to innovative breakthroughs. The weight of creativity and the dissemination of knowledge help to more accurately assess the prevalence of activities in the region and to estimate the share allocated to the creation of new hotbeds of knowledge and creativity in administrative units. New regions from countries of catch-up development [2] are reshaping the geographical map of innovations. Not only technological leadership, but investment in non-technological innovation, talent and creativity are powerful productive systems in creating added value. This impact is well researched in foreign scientific literature and is cultivated in Western society as a corporate culture.

The calculated indicators of innovation orientation in the context of communities and formed groups of indicators will be shown in Table 2. 


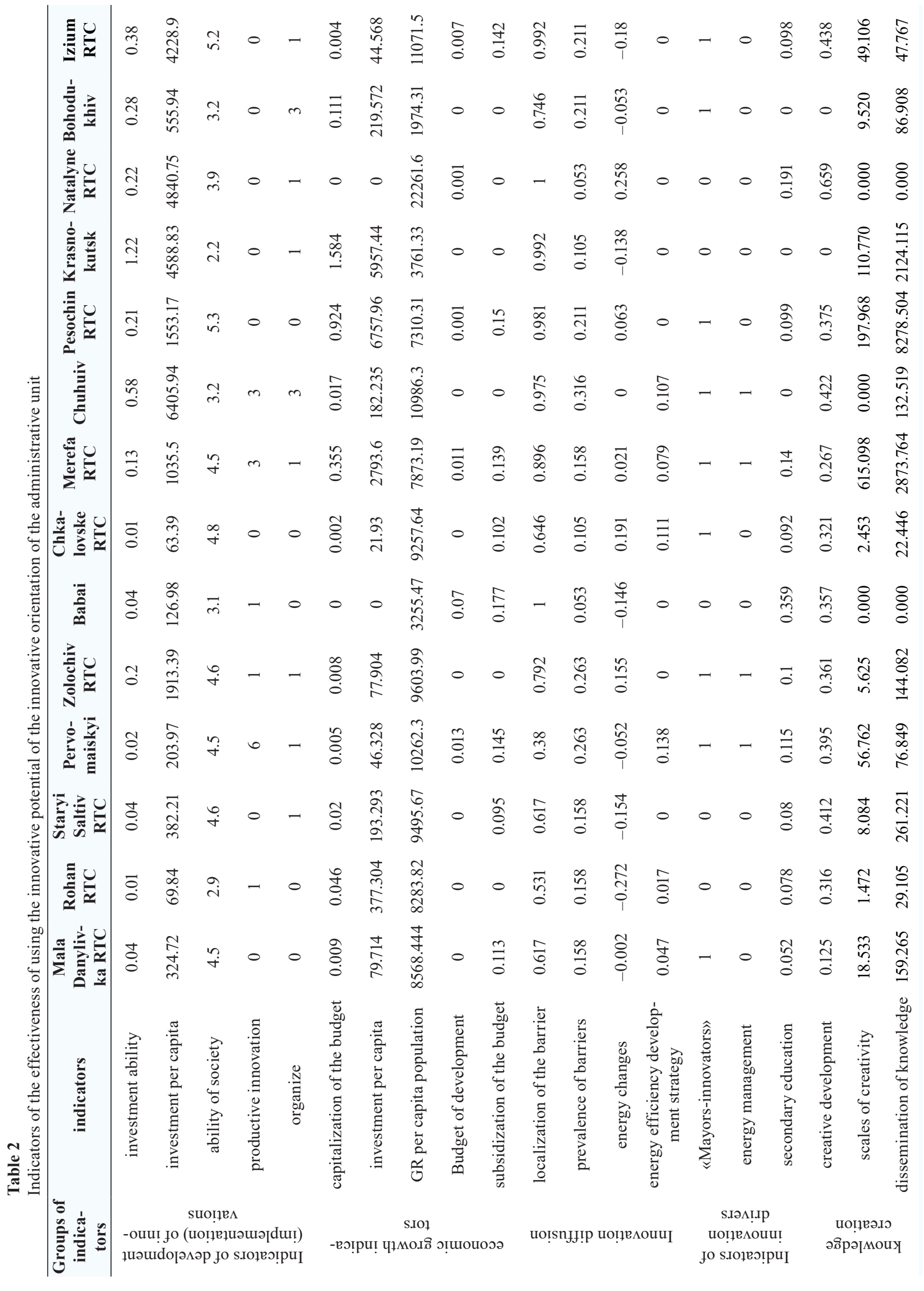


At the third stage, "Standardization of the indicators of each group," it is necessary to bring the native indicators into a comparable form. For this, the primary indicators are normalized, that is, a transition is made from absolute values to standard ones. To carry out calculations, let's differentiate the indicators for stimulants and de-stimulants. Such differentiation will make it possible to conduct an analysis more accurately, because each of the indicators has a characteristic effect on the level of development of the object under study. So, stimulants have a positive effect on the level of development of the object of research, and destimulants, on the contrary, slow down its development. In this case, stimulants are calculated by the formula:

$$
l=\frac{M-M(\min )}{M(\max )-M(\min )},
$$

and destimulants:

$$
l=\frac{M(\max )-M}{M(\max )-M(\min )},
$$

where $l$ - the value of the indicator of the block of indicators of the integral assessment; $M$ - the current value of an indicator, a block of indicators; $M(\min ), M(\max )-$ minimum and maximum value of an indicator, block of indicators.

Due to the heterogeneity of the data obtained, there was a need for standardization. The indicators obtained as a result of such normalization are in the range from 0 to 1 . The value of the integral indicator in this case will also have the range $[0 ; 1]$, facilitates the procedure for quantitative or linguistic interpretation of the integral indicator.

At the next stage, on the basis of the calculated standard values, local indicators of administrative units are determined for each group $\left(S_{i k}\right)$.

$$
S_{i k}=\sum_{i=1}^{m} l_{i j k} \cdot a_{i j},
$$

where $m$ - the number of indicators characterizing the innovative energy-efficient focus of the $i$-th group; $\alpha_{i j}$-weight coefficient of the $\mathrm{j}$-th indicator of the $i$-th group; $k$ - the number of administrative units, $(k=1 \ldots l)$ (Table 3).

To establish the weighting coefficient of the indicators, a scoring method for assessing indicators is used. The points were selected from a special rating numerical scale. Points are natural numbers from 1 to $N$ which, in decreasing order of priority, are assigned importance to each indicator of the corresponding group. Score 1 - minimum score; score $N$ - maximum.

Table 3

Calculation of local indicators for each group of indicators

\begin{tabular}{cccccc}
\hline Name of the settlement & $\begin{array}{c}\text { Indicators of } \\
\text { development of } \\
\text { innovations }\end{array}$ & $\begin{array}{c}\text { Economic growth } \\
\text { indicators }\end{array}$ & $\begin{array}{c}\text { Innovation } \\
\text { diffusions }\end{array}$ & $\begin{array}{c}\text { Indicators of } \\
\text { innovation } \\
\text { drivers }\end{array}$ & $\begin{array}{c}\text { Knowledge } \\
\text { creation }\end{array}$ \\
\hline $\mathbf{1}$ & $\mathbf{2}$ & $\mathbf{3}$ & $\mathbf{4}$ & $\mathbf{5}$ & $\mathbf{6}$ \\
\hline Mala Danylivka RTC & 0.1406 & 0.1323 & 0.4095 & 0.3604 & 0.0783 \\
Rohan RTC & 0.0759 & 0.2574 & 0.1855 & 0.0716 & 0.1564 \\
Staryi Saltiv RTC & 0.2226 & 0.1628 & 0.2405 & 0.0713 & 0.2096 \\
Pervomaiskyi & 0.4158 & 0.1500 & 0.5967 & 0.7753 & 0.2370 \\
Zolochiv RTC & 0.3253 & 0.2480 & 0.5496 & 0.7674 & 0.1904 \\
Babai & 0.0918 & 0.2007 & 0.2905 & 0.3197 & 0.1842 \\
Chkalovske RTC & 0.1435 & 0.1498 & 0.5888 & 0.4195 & 0.1750 \\
\hline
\end{tabular}


Continuation of Table 3

\begin{tabular}{cccccc}
\hline $\mathbf{1}$ & $\mathbf{2}$ & $\mathbf{3}$ & $\mathbf{4}$ & $\mathbf{5}$ & $\mathbf{6}$ \\
\hline Merefa RTC & 0.3627 & 0.2632 & 0.5835 & 0.8102 & 0.5962 \\
Chuhuiv & 0.6547 & 0.2848 & 0.8037 & 0.6796 & 0.2300 \\
Pesochin RTC & 0.2585 & 0.4256 & 0.5272 & 0.4103 & 0.6158 \\
Krasnokutsk & 0.4296 & 0.6037 & 0.3575 & 0.0000 & 0.1424 \\
Natalyne RTC & 0.3385 & 0.3996 & 0.4960 & 0.1486 & 0.3252 \\
Bohodukhiv & 0.3138 & 0.2123 & 0.3877 & 0.3359 & 0.0088 \\
Izium RTC & 0.4200 & 0.1490 & 0.4065 & 0.4148 & 0.2667
\end{tabular}

Thus, the obtained data are necessary for the transition to the fifth stage - the calculation of the integral indicator of the innovative energy-efficient orientation of the research subject. This indicator is calculated using the formula:

$$
I P=\sum_{i=1}^{q} S_{i k} \cdot \lambda_{i}
$$

where IP - the indicator of the integral assessment; $q$ - the number of blocks - indicators of the integral assessment; $\lambda_{i}$ - the impact (significance) of the $i$-th group of indicators on the integral, innovative energy-efficient focus of the administrative unit.

\section{Results}

As a research result, an indicator of innovative orientation is determined, which allows to analytically establish the feasibility of introducing innovative energy-efficient technologies in administrative units. These indicators for each object of research are shown in Table 4. The integral indicator is the result of a comprehensive assessment of the data obtained by calculating and economic and mathematical analysis of the system of specified indicators characterizing the innovative potential of the administrative units under study.

Table 4

The results of the calculations of the integral assessment

\begin{tabular}{cc}
\hline Name of the settlement & Integral assessment \\
\hline Mala Danylivka RTC & 0.226409225 \\
Rohan RTC & 0.144466091 \\
Staryi Saltiv RTC & 0.18236301 \\
Pervomaiskyi & 0.435368054 \\
Zolochiv RTC & 0.413001486 \\
Babai & 0.212590986 \\
Chkalovske RTC & 0.287090186 \\
Merefa RTC & 0.516797742 \\
Chuhuiv & 0.536560717 \\
Pesochin RTC & 0.439607084 \\
Krasnokutsk & 0.304656449 \\
Natalyne RTC & 0.337611442 \\
Bohodukhiv & 0.256016997 \\
Izium RTC & 0.334976303
\end{tabular}


For the purpose of constructing a rating of the innovative orientation of administrative units, integral indices of ranks are obtained (Fig. 4). Let's define the most and least favorable administrative units for the introduction of energy efficient innovative technologies.

For this, the results are ranked. The closer to one is the value of the integral indicator, the higher the level of innovative energy-efficient orientation has an administrative unit [8]. It is based on one of E.K. Harrington's logistic functions - the "desirability curve". When solving multicriteria problems, the Harrington function is considered one of the most convenient ranking methods. Harrington's scale, which has a universal character and consists of five intervals of the value of the integral indicator [9]:

$$
\begin{aligned}
& -0-0.2-\text { very low; } \\
& -0.2-0.37-\text { low; } \\
& -0.37-0.63-\text { medium; } \\
& -0.63-0.8-\text { high; } \\
& -0.8-1-\text { very high. }
\end{aligned}
$$

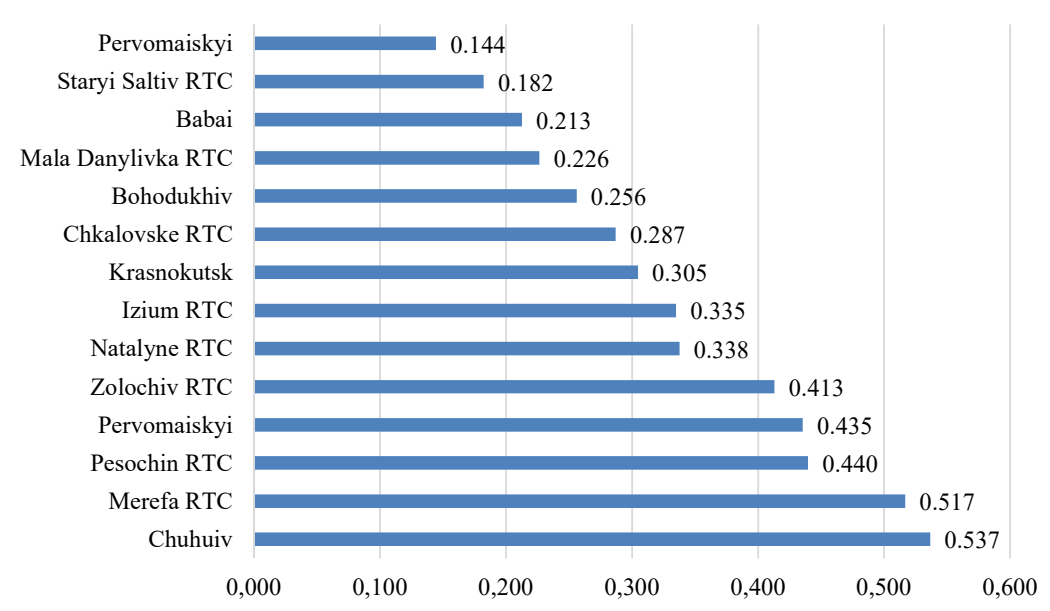

Fig. 4. Innovative orientation of the administrative units of the Kharkiv region

According to the "desirability curve", all analyzed administrative units are in the first three levels, namely very low, low and medium.

At the middle level are Chuhuiv, Merefa RTC, Pesochin RTC, Pervomaiskyi and Zolochiv RTC. These administrative units are actively introducing energy efficient technologies and applying energy efficient management. In addition, Chuhuiv and Pervomayskyi due to their status cities have the opportunity to attract funds and investors for the implementation of energy efficient programs.

Natalyne RTC, Izium RTC, Krasnokutsk, Chkalovske RTC, GBohodukhiv, Mala Danylivka RTC and Babai entered the low level in accordance with the "desirability curve".

To very low Rohan RTC and Staryi Saltiv RTC. This indicates that despite the development of these administrative units, their level of innovative energy efficient focus is not enough. Their level is not sufficient for the introduction of energy efficient technologies and the introduction of such technologies is not economically feasible.

In their development, communities should take into account that resources are finite, and needs are unlimited, and in the indicators from 0.2 to 0.8 there is a significant potential for the development of energy saving and energy efficiency, which should be achieved primarily through modern methods and tools defined by our European Cooperation and are widely represented in grant and other foreign and Ukrainian funding.

\section{Discussion}

This article is the result of a scientific study of the energy efficiency gap theory and the taxonomy of energy efficiency barriers. The indicators derived from these theories formed the basis 
for calculating the integral indicator of innovative orientation. In the study, the integral indicator was calculated sectoral, without taking into account the private and industrial sectors, expands the possibilities of scientific observation. These studies made it possible, according to certain indicators, without the use of generally accepted economic indicators, to establish the innovative environment favorable to the perception of energy efficient technologies.

The study of the feasibility of introducing energy-efficient innovative measures based on the taxonomy of barriers and the theory of energy efficiency gap was not carried out by Ukrainian scientists. The energy efficiency gap theory was derived and developed in the USA [10, 11]. Subsequently, empirical studies of the gap in energy efficiency were carried out $[12,13]$. Groups of barriers to energy conservation were formed and further divided into subgroups: institutional, market, organizational, and behavioral $[14,15]$. In further studies, new groups of technological, scientific and educational, lifestyle barriers were identified [16, 17]. However, in matters of introducing energy efficient technologies, the taxonomy of energy efficiency barriers of S. Sorrell et al. Is the most complete and detailed work as a tool for studying the energy efficiency gap $[13,18]$.

\section{Conclusions}

Integral indicators of innovative energy-efficient orientation have been established. Administrative units have been derived according to homogeneous groups of primary indicators. The use of a wide range of primary indicators makes it possible to display the quantitative and qualitative characteristics of the level of innovation orientation of the studied subjects.

The method of integral assessment of such primary indicators in the process of synthetic analysis made it possible to determine a generalized integral indicator for each subject and compare the results obtained to compare the innovative capabilities of the studied subjects. The very level of the generalized integral indicator, its mathematical value, made it possible to determine the readiness of the studied subjects for the implementation of innovative energy efficient technologies. The Harrington scale was used. The introduction of the proposed methodology, together with the ability to independently form a system of primary indicators, is an additional tool for internal assessment of innovative energy-efficient focus in a specific period of economic growth and to determine the further direction of development of the research subject.

\section{References}

[1] Bilous, L. B. (2020). Determination of energy efficiency barriers taxonomy in socio-economic model of Ukraine. Technology audit and production reserves, 3 (4 (53)), 14-21. doi: http://doi.org/10.15587/2706-5448.2020.206682

[2] Fedulova, L. I. (2014). Formation of regional innovation systems in the context of the principles of European innovation policy. Academic review, 1, 144-155. Available at: http://nbuv.gov.ua/UJRN/ao_2014_1_21

[3] Levchenko, O. M. (2017). Methodical approaches to assessing the innovation potential of regions in the context of the formation of innovation-integrated structures. Scientific works of the Central Ukrainian National Technical University. Economic sciences, 31, 28-38.

[4] Zakhozhay, V. B., Koretska, O. V. (2015). Method of calculating the integrated indicator of innovation orientation of enterprises. Naukovi pratsi MAUP, 44 (1), 158-165.

[5] European Innovation Scoreboard 2020. Available at: https://interactivetool.eu/EIS/EIS_2.html\#: :text=Performance\%20 groups $\% 20$ are $\% 20$ based $\% 20$ on, average $\% 20$ of $\% 20$ the $\% 2027 \% 20$ indicators.\&text $=$ Strong\%20Innovators $\% 3 \mathrm{~A} \% 20$ countries $\% 20$ where $\% 20$ performance, $120 \% 25 \% 20$ of $\% 20$ the $\% 20$ EU\%20average

[6] Vdovychenko, A. (2008). Pragmatism of calculation of integral index of innovative development in Ukraine. Svit finansiv, 3 (16), 154-161. Available at: http://sf.tneu.edu.ua/index.php/sf/article/view/293

[7] Community passports. Available at: https://dostup.pravda.com.ua/

[8] Pichkalev, A. V. (2012). Generalized desirability function Harrington for comparative analysis of technical means. Research Science City, 25-28.

[9] Ligonenko, L. O. (2015). Methodology and tools for evaluation of enterprise innovation. Marketing and innovation management, 3, 105-117.

[10] Blumstein, C., Krieg, B., Schipper, L., York, C. (1980). Overcoming social and institutional barriers to energy conservation. Energy, 5 (4), 355-371. doi: http://doi.org/10.1016/0360-5442(80)90036-5 
[11] Jaffe, A. B., Stavins, R. N. (1994). The energy-efficiency gap What does it mean? Energy Policy, 22 (10), 804-810. doi: http:// doi.org/10.1016/0301-4215(94)90138-4

[12] Korppoo, A. (2005). Russian energy efficiency projects: lessons learnt from Activities Implemented Jointly pilot phase. Energy Policy, 33 (1), 113-126. doi: http://doi.org/10.1016/s0301-4215(03)00207-6

[13] Ratner, S. V., Iosifova, L. V. (2014). Information barriers as a factor in reducing the rate of diffusion of new technologies. Economic analysis: theory and practice, 16 (367), 14-28.

[14] Painuly, J. P., Reddy, B. S. (1996). Electricity Conservation Programs: Barriers to Their Implementation. Energy Sources, 18 (3), 257-267. doi: http://doi.org/10.1080/00908319608908765

[15] Weber, L. (1997). Some reflections on barriers to the efficient use of energy. Energy Policy, 25 (10), 833-835. doi: http:// doi.org/10.1016/s0301-4215(97)00084-0

[16] Ratner, S. V., Iosifov, V. V. (2013). Cost barriers to the diffusion of alternative energy technologies in Russia. Economic analysis: theory and practice, 40, 25-33.

[17] Krumgolts, D. V., Markin, G. V. (2013). Topical issues of energy saving development in residential development. Journal of Legal and Economic Research, 1, 97-100.

[18] Sorrell, S., Schleich, J., Scott, S., O’Malley, E., Trace, F., Boede, U., Ostertag, K., Radgen, P. (2000). Reducing barriers to energy efficiency in public and private organizations. Brighton: Energy research centre science and technology policy research (SPRU), 31, 405-430. 